\begin{tabular}{|c|c|}
\hline & $\begin{array}{l}\text { International Journal of Trend in Scientific } \\
\text { Research and Development (IJTSRD) }\end{array}$ \\
\hline 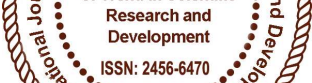 & International Open Access Journal \\
\hline 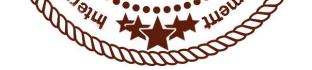 & ISSN No: 2456 - 6470 | www.ijtsrd.com | Volume - 2 | Issue - 2 \\
\hline
\end{tabular}

\title{
Optical and Microstructural Analysis of Chemically prepared Lead Sulphide (PbS) Thin Film
}

Olabisi 0.

Department of Science Laboratory Technology Ladoke Akintola University of Technology Ogbomoso, Oyo, Nigeria
Adegboyega 0.

Department of Physics Emmanuel Alayande College of Education Oyo, Oyo, Nigeria

\section{ABSTRACT}

This paper presents thin films of Lead Sulphide grown by a chemical bath deposition method, using triethanolamine as complexing agent. The films were deposited on both surface of the glass substrate at deposition time of 4hours. The effect of annealing on transmisivity and reflectivity of chemically deposited lead sulphide thin film were studied. Optical microscope and scanning electron microscope SEM were used for measurements. The average grain sizes in the as prepared films were estimated to be $1.3 \mu \mathrm{m}$ while that of the annealed film was estimated to be $2.5 \mu \mathrm{m}$.

Keywords: thin films, prepared, annealing, chemical bath deposition, optical properties, microstructures, transmittance, reflectance, prepared sample, annealed sample

\section{INTRODUCTION}

Chemical bath deposition is a widely used materials processing technology. The majority of its application involves applying solid thin-film coatings to surfaces, but it is also used to produce high-purity bulk materials and powders, as well as fabricating composite materials via infiltration techniques [1]. Lead sulphide is a semiconductor material with an approximate energy band gap of $0.4 \mathrm{eV}$ at $300 \mathrm{~K}$ [2]. These properties make $\mathrm{PbS}$ very suitable for infrared detection application. This material has also been used in photography, solar absorption. In addition, $\mathrm{PbS}$ has been utilized as photo-resistance, diode lasers, humidity and temperature sensors, decorative and solar control coatings [3, 4]. These properties have been correlated with the growth conditions and the nature of substrates. For these reasons, many research groups have shown a great interest in the development and study of this material the properties exhibited and determine the transmittance and reflectivity when annealed. Then viewing the $\mathrm{PbS}$ samples developed under optical microscope and electron microscope to know the microstructural properties $[5,6]$.

There are several methods used in photoacelerated chemical deposition, microwave heating [7]. Chemical bath deposition is presently attracting considerable attention as it does not require sophisticated instrumentation [8]. It is relatively inexpensive, easy to handle, convenient for large area deposition and capable of yielding good quality thin films. The characteristics of chemically deposited $\mathrm{PbS}$ thin films by CBD strongly depend on growth conditions. In this paper, we report the structural and optical properties of annealed $\mathrm{PbS}$ thin films obtained by CBD method for 4 hours.

\subsection{Experimental}

\subsection{Synthesis of lead sulphide}

The $\mathrm{PbS}$ thin films were grown on ordinary glass slide $(5 \mathrm{~cm} \times 5 \mathrm{~cm} \times 2 \mathrm{~mm})$ substrates. The deposition was done in a reactive solution prepared were constituted from aqueous solution of 1.0 mole of lead acetate, 1.0 mole of thiourea and 1.0 mole Tri-Ethanol Amino 
(TEA). Sodium Hydroxide $(\mathrm{NaOH})$ was added to the solution to give a $\mathrm{pH}$ value between 9 and 10 . Cleaned substrates were vertically immersed into the solution. The concentration of the reagents, at $\mathrm{pH}$ (between 9 and 10) with temperature of $300 \mathrm{~K}$ was considered for deposition time for $4 \mathrm{hrs}$. The formation of $\mathrm{PbS}$ thin film involves the following chemical reactions.

$$
\begin{array}{ll}
\mathrm{Sc}\left(\mathrm{NH}_{2}\right)+\mathrm{OH} & \longrightarrow \mathrm{CH}_{2} \mathrm{~N}_{2}+\mathrm{H}_{2} \mathrm{O}+\mathrm{HS} \\
2 \mathrm{HS}+2 \mathrm{OH} & \longrightarrow 2 \mathrm{H}_{2} \mathrm{O}+\mathrm{S}_{2} \\
\mathrm{~Pb}^{2+}+\mathrm{S}^{2+} & \longrightarrow \mathrm{PbS}
\end{array}
$$

Glass substrates were removed after 4hours deposition time. One sample was set aside as prepared and the other samples were placed in electric oven for anneling at $423 \mathrm{~K}$ for 1 hour [9]

\subsection{Results and Discussion}

\subsection{Microstructure}

The films were structurally characterized by scanning electron microscope (model XL 20 SEM) with working voltage of $40 \mathrm{kV}$ and current $10 \mathrm{~mA}$ at

$(\lambda=1.54040 \mathrm{~A})$. The micrograph from SEM for both prepared and annealed samples were shown in Fig. 1 and 2 respectively. The micrograph in Fig. 1 shows a pyramidal shape with a compact surface without any fissures, faults and disturbances. There was presence of precipitates on the sample surface with poor crystalline structure. The micrograph in Fig. 2 shows, the formation of new grains in the recrystallized region. It shows less dislocation density. It was also noticed that the average grain size for the prepared sample was $1.8 \mu \mathrm{m}$ while that of annealed sample was found to be $2.5 \mu \mathrm{m}$.

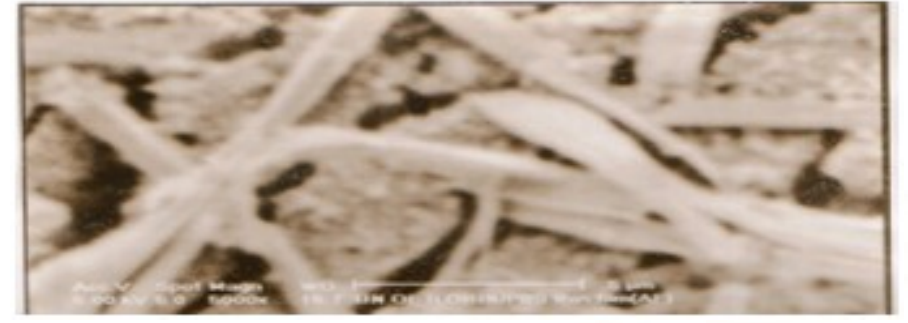

Figure 1: The micrograph from SEM for prepared sample

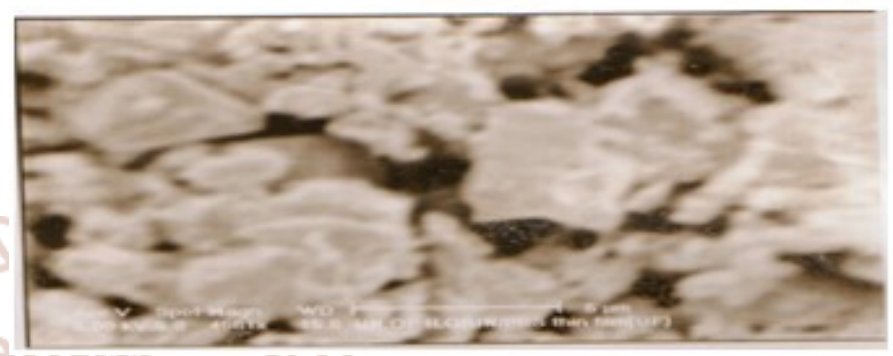

Figure 2: The micrograph from SEM for annealed

Transmittance and reflectance measurements at nearnormal incidence were performed over a spectral ranging between $0.30 \mu \mathrm{m}$ and $0.70 \mu \mathrm{m}$ thin films deposited on glass substrate using optical microscope. Fig 3 shows the optimal transmission spectra of prepared and annealed samples of lead sulphide. It was observed that the higher transmittance of $70 \%$ was obtained for annealed sample while that of prepared sample is $50 \%$ at $0.70 \mu \mathrm{m}$ wavelength. Fig 4 shows the optical reflectance spectra of the prepared and annealed samples of the lead sulphide. It was observed that the reflectance of the annealed sample is $6 \%$ while that of prepared is $12 \%$ at $0.70 \mu \mathrm{m}$, at $0.30 \mu \mathrm{m}$ wavelength the reflectance of the prepared sample is $0 \%$ while that of annealed sample is $2 \%$.

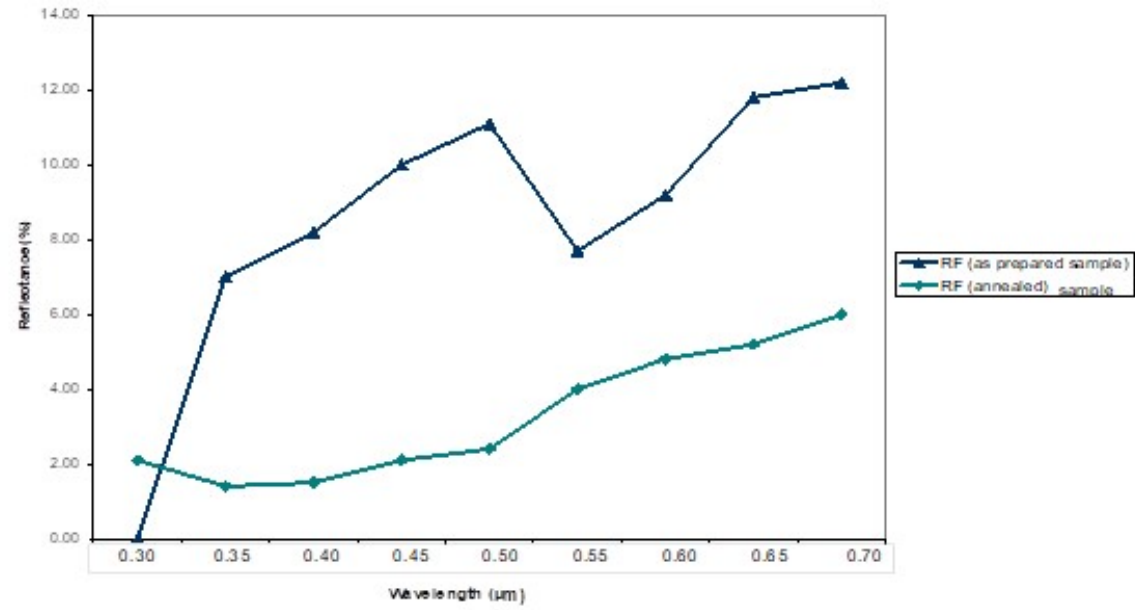

Figure 3: Variation of reflectance with wavelength $(\mu \mathrm{m})$ for as prepared and annealed PbS sample 


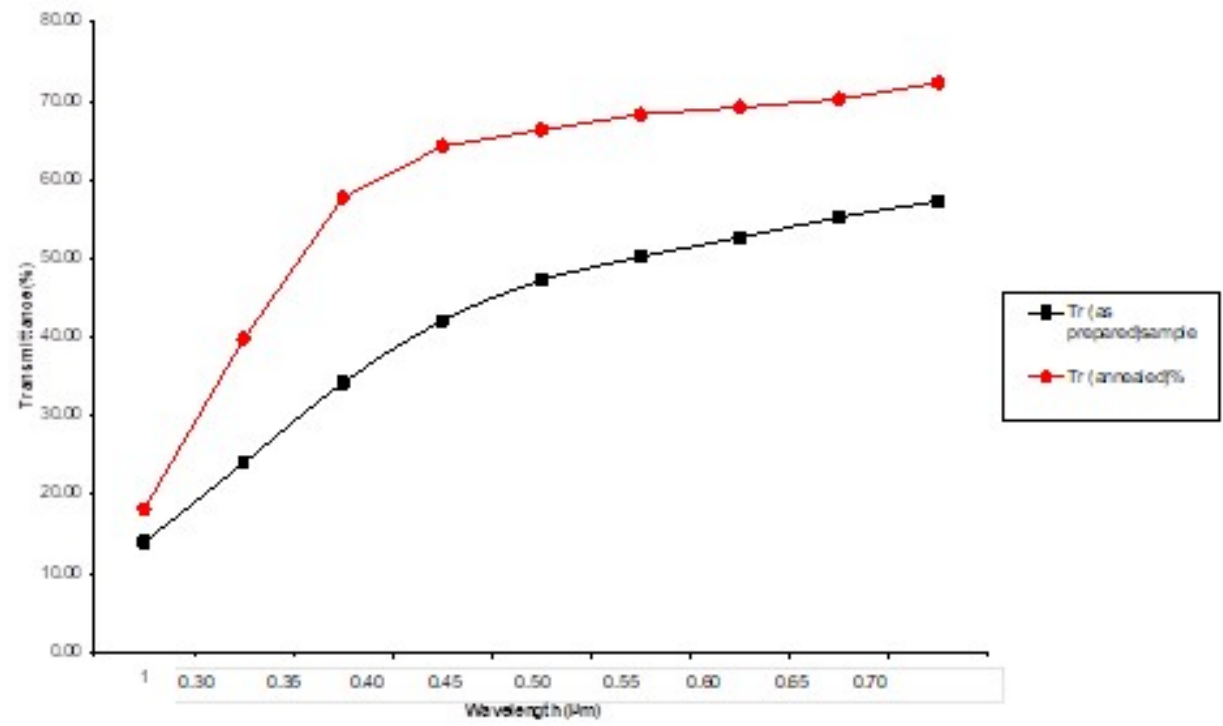

Figure 4: Variation of transmittance with wavelength $(\mu m)$ of as prepared and annealed $\mathrm{PbS}$ samples

\section{Conclusion}

In this study, the PbS were prepared by chemical bath deposition (CBD). The optical, microstructural studies of the $\mathrm{PbS}$ thin films were carried out. It was observed from the optical micoscope that higher values of transmittance and lower value of reflectance were obtained for annealed $\mathrm{PbS}$. The micrograph of annealed sample presents a good formation of new grains in the recrystallized region with less dislocation density.

\section{References}

1. Yakuphanoglu F. and Viswanathan C. "Electrical Conductivity and single oscillator model properties of amorphous CuSe semiconductor thin film". Journal of non-crystalline solids. 2007; 35(30-31): 2934-2937.

2. Soundarajan T., Kolandavel M., and Suresh S., "Investigation of the structural, Optical and Electrical properties of Copper Selenide thin films". Journal of Material Research. 2015; 18(5): 1000-1007.

3. Thirumavalovan S., Mani K., and Suresh S. "Investigation on Structural, Optical, Morphological and Electrical properties of Lead Sulphide (PbS) Thin Films". Journal of Ovonic Research. 2015; 11(3): 123-130.

4. Ezekoroye B.A, Emeakaroha V.A, Ezekorroye V.A, Ighodalo K.O and Offor P.O. "Optical and Structural properties of Lead Sulphide $(\mathrm{PbS})$ thin films synthesized by chemical method.
International Journal of Physical Sciences. 2015, 10(13): 385-390.

5. Abulmakarim M., Rufai I.A, and Musa A.O, "Investigation of the properties of Cadmium Sulphide thin films for solar cell Applications" International Journal of Energy Engeneering. 2014, 4(3): 61-67.

6. Dipalee J., Shaikh S., and Saddiqui F. "Effect of annealing on Structural and Optoelectronic properties of CdS thin films by SILAR method. Journal of Advance in Applied Research, India, 2011; 2(4): 417-425.

7. Khomane S., "Crystallographic, morphological, optical and electrical properties of CBD deposited Cadmium Sulphide films. Archives of Applied Science Research, 2011, 3(5): 273-279.

8. Kathirvel D., Sariyana N., Prabahar S., and Srikath R., "Electrical properties of chemical bath deposited Cadmium Sulphide thin film. International Journal of graphic and multimedia, 2011,2(1): 37-44.

9. Seghaiver S., Kamoun N., Brini R., and Amara A.B "Structural and Optical properties of PbsS thin films deposited by chemical bath deposition" Journal of Materials Chemistry and Physics, Elservier. 2005; 2006(7): 71-80. 